\title{
Extracorporeal Membrane Oxygenation Support on Acute Fulminant Myocarditis Associated with Parainfluenza Infection: A Case Report
}

\author{
Melis Akpınar1, (D) Fatih Aygün2, (D) Ahmet İrdem³ \\ ${ }^{1}$ Karasu State Hospital, Clinic of Pediatrics, Sakarya, Turkey \\ 2istanbul University-Cerrahpaşa, Cerrahpasa Faculty of Medicine, Department of Pediatric Intensive Care Unit, Istanbul, Turkey \\ 3 University of Health Sciences Turkey, Prof. Dr. Cemil Taşçığlu City Hospital, Clinic of of Pediatric Cardiology, İstanbul, Turkey
}

\section{Abstract}

Acute fulminant myocarditis (AFM) is a clinical condition that can lead to sudden onset of rapidly progressing cardiogenic shock with significant arrhythmia and possible cardiac arrest. Mechanical circulation support has been reported to provide effective cardiac support in patients with AFM. In this article, we aimed to present the case of a 14-year-old girl with AFM who experienced a cardiogenic shock and resistant ventricular tachycardia unresponsive to medical treatment; however, she could be successfully treated with veno-arterial extracorporeal membrane oxygenation and discharged without neurological sequelae from the hospital.

Keywords: Extracorporeal membrane oxygenation, cardiogenic shock, myocarditis, parainfluenza, ventricular tachycardia

\section{INTRODUCTION}

Acute fulminant myocarditis (AFM) is a clinical condition that can lead to sudden onset of rapidly progressing cardiogenic shock with significant arrhythmia and possible cardiac arrest. In patients with AFM who are unresponsive to medical treatment, mechanical circulation support can provide effective cardiopulmonary support (1-3).

In this article, we have presented the case of a 14-yearold girl with AFM who experienced cardiogenic shock and resistant ventricular tachycardia (VT) unresponsive to medical treatment, which was successfully treated with veno-arterial (VA) extracorporeal membrane oxygenation (ECMO).

\section{CASE PRESENTATION}

A previously healthy 14-year-old girl was admitted to the emergency service with the complaint of upper respiratory tract infection for a week. She then developed complaints of shortness of breath, fatigue, cough, and palpitations the next day. On physical examination, the patient's general condition seemed poor. She showed dyspnea and tachypnea, and had 87\% oxygen saturation, 40/min respiratory rate, 190-bpm heart rate, and 90/50 $\mathrm{mmHg}$ blood pressure, with subcostal and intercostal retractions. On auscultation, bilateral breath sounds were decreased in the lower zones and extensive crepitation rales were present. On posterio-anterior chest X-ray, bilateral blunting of the costophrenic and cardiophrenic angles as well as paracardiac infiltrationwas observed (Figure 1).

The patient's blood test examination results were as follows:

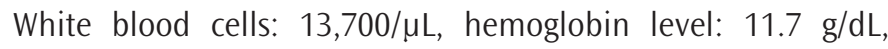
platelet count: 133,000/ $\mu \mathrm{L}$, sodium level: $130 \mathrm{mmol} / \mathrm{L}$, potassium level: $4.8 \mathrm{mmol} / \mathrm{L}$, calcium: $8.2 \mathrm{mg} / \mathrm{dL}$, lactate dehydrogenase: $878 \mathrm{U} / \mathrm{L}$, aspartate aminotransferase (AST): $471 \mathrm{U} / \mathrm{L}$, alanine aminotransferase (ALT): $696 \mathrm{U} / \mathrm{L}$, C-reactive protein: $9.1 \mathrm{mg} / \mathrm{L}$, urea: $46 \mathrm{mg} / \mathrm{dL}$, creatinine level: $0.76 \mathrm{mg} / \mathrm{dL}$, prothrombin time: 25.9 s (9.6-14.1), activated partial thromboplastin time: 
$33.4 \mathrm{~s}$ (19-33), international normalized ratio: 2.32 (0.8-1.2), in the venous blood gas $\mathrm{pH}: 7.42, \mathrm{pCO}_{2}: 33.5, \mathrm{HCO}_{3}: 21.4$, base excess: 2.29 , lactate level: $1.6 \mathrm{mmol} / \mathrm{L}$ (the values between brackets refer to normal ranges). The patient was admitted with the diagnosis of pneumonia and pleural effusion. Due to complaints of chest pain and hypoxemia and VT observed in electrocardiography (Figure 2), the patient was transferred to the pediatric intensive care unit (PICU). Consent was obtained from the patient.

Transthoracic echocardiography (TTE) demonstrated large heart cavities in the left portion (left ventricular end-diastolic diameter: $54 \mathrm{~mm}$ ), decreased systolic ejection fraction [(EF) 34\%], and moderate insufficiency in the mitral valve (Figure 3).

The patient's condition was considered as AFM because of the rapid deterioration. Amiodarone was intravenously (IV) administered with a loading dose of $5 \mathrm{mg} / \mathrm{kg}$ twice for VT. However, due to continued VT, lidocaine $(1 \mathrm{mg} / \mathrm{kg} / 10 \mathrm{~min})$ was administered as a loading dose and $25 \mu \mathrm{g} / \mathrm{kg} / \mathrm{min}$ IV infusion as a mainteinance dose. The blood test results revealed creatine

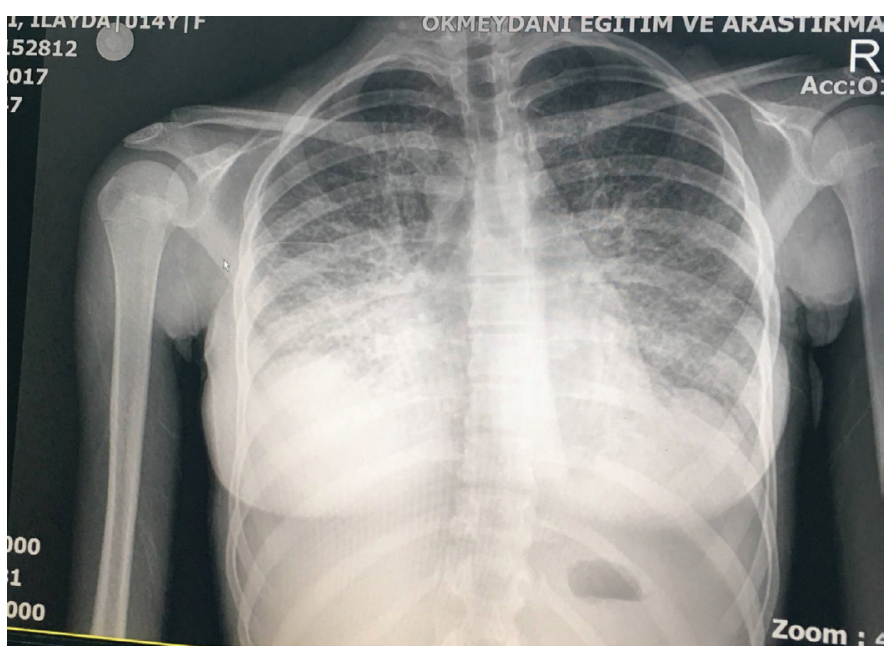

Figure 1. Patient's chest X-Ray kinase myocardial band level of $6.5 \mathrm{U} / \mathrm{L}(0.6-6.3)$ and troponin level of $0.87 \mathrm{ng} / \mathrm{mL}(0.01-0.04)$.

After $12 \mathrm{~h}$ of admission to the PICU, the patient's blood tests were repeated, and the results were as follows: AST: 1,803 U/L, ALT: $1,679 \mathrm{U} / \mathrm{L}$, urea: $63 \mathrm{mg} / \mathrm{dL}$, albumin: $0.61 \mathrm{~g} / \mathrm{dL}$, venous blood gas pH: $7.38, \mathrm{pCO}_{2}: 30.1, \mathrm{HCO}_{3}: 19.5$, BE: -6.5, and lactate: 11.3. The patient was connected to a mechanical ventilator with endotracheal entubation, and due to hypoperfusion, IV milrinone $(0.5 \mathrm{mcg} / \mathrm{kg} / \mathrm{min})$ and low-dose IV noradrenalin $(0.06$ $\mathrm{mcg} / \mathrm{kg} / \mathrm{min}$ ) were initiated as inotropic therapy; amiodarone dose was increased to $15 \mathrm{mg} / \mathrm{kg} /$ day; and lidocaine dose was also increased to $50 \mathrm{mcg} / \mathrm{kg} / \mathrm{min}$ for resistant VT. Meanwhile, $1 \mathrm{~g} / \mathrm{kg}$ IV immunoglobulin, $1 \mathrm{~g}$ pulse steroid, and $1 \mathrm{~g} / \mathrm{kg}$ of $20 \%$ human albumin were also adminsitered.

After $2 \mathrm{~h}$, the patient's condition worsened. Systemic hypoperfusion (with metabolic acidosis, hypoxemia, and lactate elevation), hypotension $(80 / 45 \mathrm{mmHg}$ ), and decreased EF in TTE (EF 10\%) were observed. Because of the resistant cardiogenic shock and VT, the patient was connected to a VA-ECMO system. The cannulation sites were femoral artery with 18-F cannulae and jugular vein with 24-F cannulae. Then, the frequency of VT decreased. TTE was performed daily. EF was then gradually increased (on the $8^{\text {th }}$ day of ECMO EF was 45\%). VA-ECMO support was discontinued after $188 \mathrm{~h}$. The tracheal aspirate sample was tested using multilocus polymerase chain reaction, and the sample was positive for parainfluenza virus. However, because of the hemodynamic stability and increased EF (to 45\%), ribavirin was not administered. No complications were observed related to ECMO.

After the discontinuation of ECMO, VT was continued, and flecainide was administered instead of lidocaine, because of the 7-day maximum dose restriction. Beta blocker was also added to the regime. After 2 days, the patient was extubated, supported with a continuous positive airway pressure, and no additional oxygen was provided.

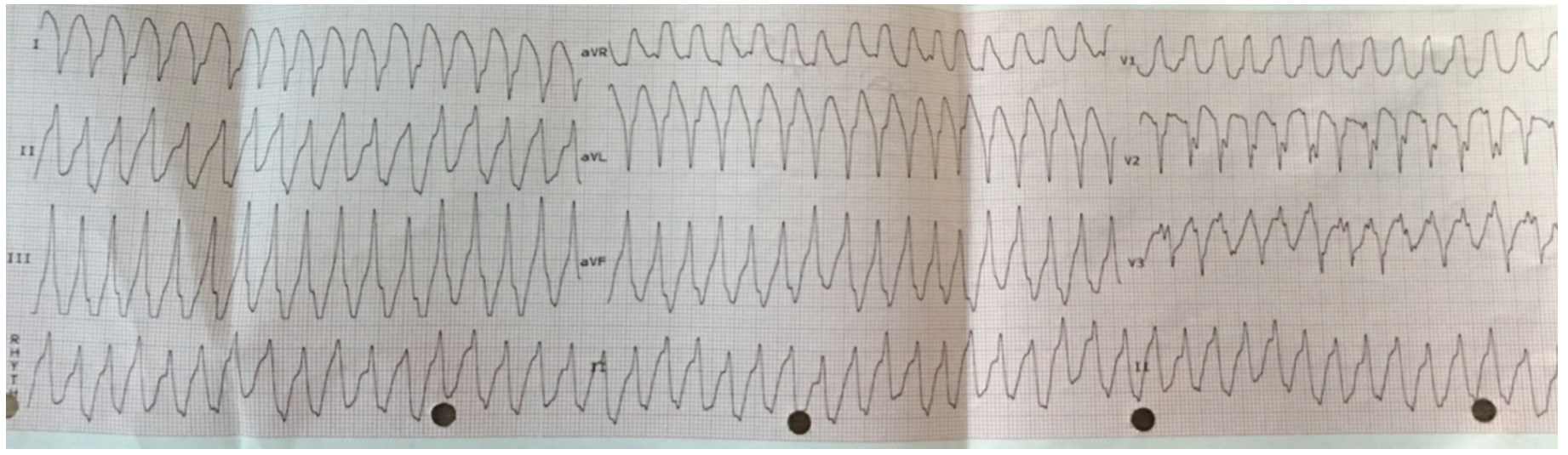

Figure 2. Patient's electrocardiogram with ventricular tachycardia 


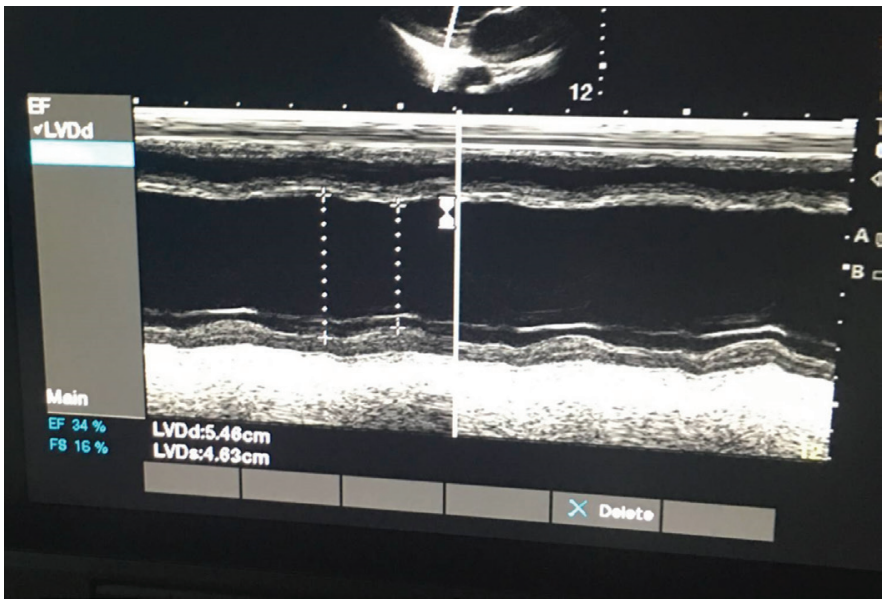

Figure 3. Patient's transthoracic echocardiogram

The frequency and duration of arrthymia was decreased gradually and finally stopped. TTE before discharging from the hospital revealed that the left heart cavities were enlarged (left ventricular end-diastolic volume: $54 \mathrm{~mm}$ ), left ventricular EF was $47 \%$, and moderate mitral regurgitation with central origin was present. The patient was discharged from the hospital with no neurological sequelae, and triple antiarrhythmic drugs, enalapril, and furosemide were prescribed.

\section{DISCUSSION}

The clinical condition of pediatric patients with AFM can worsen rapidly and unpredictably within hours of first presentation. AFM involves acute illness with hemodynamic derangement and ventricular arrhythmias due to a severe inflammatory process, and patients require the support of cardiac pump function and/ or the urgent management of serious arrhythmias (4).

The selection of an appropriate therapy for ventricular arrhythmias focused on the prevention of sudden cardiac death and associated medical conditions. The management of arrhythmia may include appropriate antiarrhythmic therapy with drugs, implantable devices, ablation, or surgery. A beta blocker and amiodarone were recommended for recurrent polymorphic VT. IV lidocaine may be considered for the treatment of recurrent sustained VT or ventricular fibrillation (VF) in patients not responding to beta-blockers or amiodarone. Electrical cardioversion or defibrillation is recommended in patients with sustained and haemodynamically untolerated VT or VF. Urgent coronary angiography is indicated in these patients for revascularization when considering myocardial ischemia. Radiofrequency catheter ablation with the implantation of a left ventricular assist device/implantable cardioverter defibrillator should be considered in patients with recurrent VT or VF not responding to revascularization and optimal medical treatment. When the conventional therapy of medication, implantable devices, and ablation fails to convert refractory VT, leading to cardiogenic shock, ECMO can be performed for maintaining the hemodynamic stability and end-organ perfusion until further decision or recovery $(5,6)$. In our case, ECMO was considered as the mechanical support for AFM because of sustained ventricular tachyarrythmia unresponsive to medical treatment and infeasible radiofrequency catheter ablation. However, the outcomes after ECMO for cardiac insufficiency in children are associated with underlying diseases (7). In a meta-analysis about the clinical outcomes in pediatric patients hospitalized with AFM and treated with ECMO, the survival rates were reported to be between $53.8 \%$ and $83.3 \%$ (8). Li et al. (9) reported the case of a 9-year-old girl with AFM, who rapidly worsened into pulseless VT and refractory cardiac arrest despite prolonged cardiopulmonary resuscitation for nearly $180 \mathrm{~min}$ and multiple antiarrhythmic therapy. They performed ECMO, and the girl recovered with intact cardiac and neurocognitive functions after $221 \mathrm{~h}$ of ECMO treatment. Similarly, in our report, after 188 hof ECMO treatment, our patient successfully recovered without cardiac and neurocognitive damage.

Recent reports with larger cohorts indicated that AFM is associated with overall worse outcomes that included lower left ventricular EF at the last follow-up, higher in-hospital mortality, and increased rates of cardiac transplantation (8-11). Mechanical circulation support can be considered at the first line of treatment. The disease has a high mortality unless provided with effective and on-time intervention with mechanical circulation support. The survival rate of patients with mechanical circulation support can rise up to $80 \%$. Especially, in case of cardiogenic shock and resistant VT, mechanical circulation support is a good option for reducing the mortality rate and increasing the healing rate of myocardial muscles. As alternatives to mechanical circulation support, intra-aortic balloon pump, percutaneous cardiopulmonary support system, and ventricular assist device can be used. However, in children, ECMO is used more frequently because of its ease of use, low invasiveness, and more effective outcomes $(3,12,13)$.

Viral infections are frequently the preliminary etiology of AFM. However, parainfluenza-related myocarditis has been less frequently reported $(14,15)$. Parainfluenza virus was detected in the tracheal aspiration fluid of our patient. Ribavirin can be used as an antiviral agent (14-16). However, due to the fact that our patient's renal function was insufficient and EF increased to $40 \%$, 
ribavirin was not used. In addition, there are only limited studies available on the use of ribavirin in respiratory tract infections caused by parainfluenza virus. However, studies on whether IV immunoglobulin is effective or not has been reported in the past (15-17).

Our patient was administered pulse methylprednisolone with pentaglobulin. Corticosteroids reduce the amount of $T$ lymphocytes, which are the mediators of ongoing heart damage in AFM through lysis. With a reduced number of T lymphocytes, cardiac ventricular function has been reported to improve (1517).

\section{CONCLUSION}

Treatment of cardiogenic shock and resistant VT related to AFM should involve a multidisciplinary approach, such as mechanical circulation support, antiarrhythmic drugs, inotropic drugs, immunoglobulin, steroids, and other supportive treatments.

\section{Ethics}

Informed Consent: Consent was obtained from the patient.

Peer-review: Externally peer-reviewed.

\section{Authorship Contributions}

Concept: A.I., F.A., Design: A.I., F.A., Data Collection or Processing: M.A., F.A., Analysis or Interpretation: M.A., F.A., Literature Search: M.A., Writing: M.A.

Conflict of Interest: No conflict of interest was declared by the authors.

Financial Disclosure: The authors declared that this study received no financial support.

\section{REFERENCES}

1. Elliott P, Andersson B, Arbustini E, Bilinska Z, Cecchi F, Charron P, et al. Classification of the cardiomyopathies: a position statement from the European Society Of Cardiology Working Group on Myocardial and Pericardial Diseases. Eur Heart J 2008;29:270-6.

2. Sinagra G, Anzini M, Pereira NL, Bussani R, Finocchiaro G, Bartunek J, et al. Myocarditis in Clinical Practice. Mayo Clin Proc 2016;91:1256-66.

3. Mani A, Shankar S, Tan TH, Wong KY. Extracorporeal membrane oxygenation for children with fulminant myocarditis. Asian Cardiovasc Thorac Ann 2010;18:131-4.
4. Sharma AN, Jacob RandolphStultz JR, Bellamkonda N, Amsterdam EA. Fulminant Myocarditis: Epidemiology, Pathogenesis, Diagnosis, and Management. The American Journal of Cardiology 2019;124:1954-60.

5. Brunner ME, Siegenthaler N, Shah D, Licker MJ, Cikirikcioglu M, Brochard L, et al. Extracorporeal membrane oxygenation support as bridge to recovery in a patient with electrical storm related cardiogenic shock. Am J Emerg Med 2013;3:467.

6. Priori SG, Blomström-Lundqvist C, Mazzanti A, Blom N, Borggrefe M, Camm J, et al. [2015 ESC Guidelines for the management of patients with ventricular arrhythmias and the prevention of sudden cardiac death]. Kardiol Pol 2015;73:795-900.

7. Merrill ED, Schoeneberg L, Sandesara P, Molitor-Kirsch E, O'Brien J Jr, Dai $\mathrm{H}$, et al. Outcomes after prolonged extracorporeal membrane oxygenation support in children with cardiac disease--Extracorporeal Life Support Organization registry study. J Thorac Cardiovasc Surg 2014;148:582-8.

8. Xiong H, Xia B, Zhu J, Li B, Huang W. Clinical Outcomes in Pediatric Patients Hospitalized with Fulminant Myocarditis Requiring Extracorporeal Membrane Oxygenation: A Meta-analysis. Pediatr Cardiol 2017;38:209-14.

9. Li YT, Yang LF, Chen ZG, Pan L, Duan MQ, Hu Y, et al. ECMO as an effective rescue therapeutic for fulminant myocarditis complicated with refractory cardiac arrest. Ther Clin Risk Manag 2017;13:1507-11.

10. Ammirati E, Cipriani M, Lilliu M, Sormani P, Varrenti M, Raineri C, et al. Survival and Left Ventricular Function Changes in Fulminant Versus Nonfulminant Acute Myocarditis. Circulation 2017;136:529-45.

11. Ammirati E, Cipriani M, Moro C, Raineri C, Pini D, Sormani P, et al. Clinical presentation and outcome in a contemporary cohort of patients with acute myocarditis multicenter Lombardy registry. Circulation 2018;138:1088-99.

12. Ning B, Zhang C, Lin R, Tan L, Chen Z, Yu J, et al. Local experience with extracorporeal membrane oxygenation in children with acute fulminant myocarditis. PLoS One 2013;8:82258.

13. Yamamoto LG, Young LL. Acute-onset dysrhythmia heralding fulminant myocarditis and refractory cardiac arrest treated with ED cardiopulmonary bypass and extracorporeal membrane oxygenation. Am J Emerg Med 2007;25:348-52.

14. Maisch B, Ruppert V, Pankuweit S. Management of fulminant myocarditis: a diagnosis in search of its etiology but with therapeutic options. Curr Heart Fail Rep 2014;11:166-77.

15. Kalimuddin S, Sessions OM, Hou Y, Ooi EE, Sim D, Cumaraswamy S, et al. Successful clearance of human parainfluenza virus type 2 viraemia with intravenous ribavirin and immunoglobulin in a patient with acute myocarditis. J Clin Virol 2013;56:37-40.

16. Isogai T, Yasunaga H, Matsui H, Tanaka H, Horiguchi H, Fushimi K. Effect of intravenous immunoglobulin for fulminant myocarditis on inhospital mortality: propensity score analyses. J Card Fail 2015;21:391-7.

17. Ison MG. Antiviral Treatments. Clin Chest Med 2017;38:139-53. 